OPEN ACCESS

Edited by:

Masoumeh Velayati,

University of Warwick,

United Kingdom

Reviewed by:

Nitasha Nagaraj,

George Washington University,

United States

Indranil Saha,

Indian Council of Medical Research

(ICMR), India

*Correspondence:

Sweety Suman Jha

swty.jha06@gmail.com

Specialty section: This article was submitted to Gender, Sex and Sexualities,

a section of the journal

Frontiers in Sociology

Received: 07 September 2021 Accepted: 13 December 2021

Published: 03 February 2022

Citation:

Lahiri A and Jha SS (2022) Gender Equity Perceptions Among SchoolGoing Adolescents: A Mixed-Methods Comparison Amongst Tribal and NonTribal Rural Areas of an Eastern State

\section{Gender Equity Perceptions Among School-Going Adolescents: A Mixed-Methods Comparison Amongst Tribal and Non-Tribal Rural Areas of an Eastern State in India}

\author{
Arista Lahiri and Sweety Suman Jha* \\ Community Medicine, Dr. B. C. Roy Multi Speciality Medical Research Centre, Indian Institute of Technology, Kharagpur, India
}

Introduction: Gender equity is an important social determinant of population health. There are very few studies in the Indian context in this regard, and even less regarding the diversity in tribal-dominated and non-tribal regions. The current study was conducted to assess and compare the perceptions of adolescents going to selected schools of tribaldominated and non-tribal rural areas in West Bengal, India, regarding gender equity. It also explored the teacher's perceptions on gender equity in an attempt to contextualize the students' perceptions.

Methods: A mixed-methods study was conducted with a convergent parallel design in two co-education schools, each from tribal-dominated and non-tribal rural areas. In the quantitative survey total of 828 adolescents aged $14-19$ years participated. The qualitative component involved 26 in-depth interviews (IDIs) with the selected teachers.

Results: Overall, the respondents from tribal area had a better perception regarding the equitable privilege of independence among genders, equity in decision roles, and especially financial decision roles of women. Perceptions related to girls access to education were better among the boys from non-tribal area than their counterparts from tribal area. The non-tribal respondents had a more inadequate perception regarding women's limited role. In general, the respondents perceived favorably against gender dominance. The teacher's perceptions in the context were mostly concordant, with some exceptions, e.g., regarding dominance and violence-related issues, the teachers perceived differently, contrasting the better perceptions exhibited by the students.

Conclusion: The teachers' perceptions showed strict reliance on the deep-rooted social norms that can be taken up for behavior change interventions. Better perceptions from the tribal areas are an opportunity to further enhance on gender equity. The boys' perceptions can still be improved more in favor of gender equity.

Keywords: adolescent, gender-equity, gender-roles, gender-based violence, perception, tribal, mixed-methods research 


\section{INTRODUCTION}

The concept of gender equity, a critical social determinant of population health, has been gradually emerging as an area of prime importance to researchers (Phillips, 2005; Vlassoff, 2007; United Nations, 2010; World Health Organization, 2021). The term "gender" denotes the differences in social roles and their fulfillment. Heavily affected by prevalent social values and normative practices, gender-inequity is often cemented by gender discrimination in various functions despite no plausible explanation through biological differences in sexes (Braveman and Gruskin, 2003; Vlassoff, 2007). Gender inequity fueled by gender discrimination is globally considered to contribute to the growing burden of non-communicable and infectious diseases (Kim, 1990; Rathgeber and Vlassoff, 1993; Vlassoff and Manderson, 1998; Vlassoff, 2007; World Health Organization, 2019). The inequalities are perceived as deep-rooted and acculturated among backward, hard to reach, and marginalized areas, e.g., in some tribal-dominated regions (Vilms et al., 2017; Landry et al., 2019). This is often coupled with poor population health and poor healthcare access (Braveman and Gruskin, 2003).

Gender-equity as a whole has been a less studied topic in the Indian context concerning population health. The majority of the discussions are theoretical, with only a few studies to evaluate the empirical evidence regarding gender equity as a social determinant of health. These studies, however, revealed a situation nested in poverty, social adversity to women, and unjustifiably retrenched healthcare behavior with a hidden burden of morbidity, which is anything but far from equity (Brahmapurkar, 2017; Vilms et al., 2017; Landry et al., 2019). As per the recent data from National Family Health Survey 5 (NFHS-5), nearly half of the young married women surveyed were married before attaining the age of 18 years, one-fifth of the rural women had employment over past 1 year and property ownership, and nearly one-third of the ever-married women reported to have experienced spousal violence (Ministry of Health and Fa, 2021). Despite this challenging situation, literature on gender-equity are scarce in West Bengal.

The situation among marginalized or backward areas, e.g., tribal belt, requires an in-depth understanding, especially in contrast with non-marginalized areas. To understand the difference better and more precisely, search for possible prospective interventions to deal with this long-standing social problem; the school-going children's, in particular, the late adolescent's perspectives are cardinal, especially in the backdrop of their teacher's perception of the same issue (Kolip and Schmidt, 1999; Jha et al., 2020). Informed by prior literatures, the comprehensive understanding of gender-equity among the adolescents was based on issues of independence, decision roles, access, competency in different roles, dominance and control, and idea regarding family sustainability (Dhal, 2018; Landry et al., 2019; Jha et al., 2020; Nanda; Vyas et al., 2020).

Grounded on the delicacy and complexity of the topic, an integrated approach through quantitative assessment of student's perception along with an in-depth qualitative exploration of the teacher's perspectives can effectively produce the desired yield utilizing the complementing strengths of both methodologies (Mägi, Biin, Trasberg, Kruus; Creswell, 2014). The current study thus, aimed to assess and compare the perceptions of adolescents going to selected schools of tribal and non-tribal rural areas in West Bengal, India, regarding gender equity. This study also explored the teacher's perceptions on gender equity in an attempt to contextualize the student's perceptions.

\section{MATERIALS AND METHODS}

\section{Study Design}

A mixed-methods study was conducted with a convergent parallel design from August 2019 to January 2020. The data collection for the qualitative and quantitative parts was done simultaneously. The study was conducted in four rural higher secondary co-education schools in the southern part of West Bengal, India. Two schools were situated in the tribal-dominated rural fields of West Medinipur district, and the remaining two schools were located in rural areas of North 24 Parganas district, which was not a tribal-dominated area.

\section{Study Participants}

Students of classes eight to twelve aged 14-19 years studying in the selected co-education rural schools of the study areas, who provided assent and whose parents provided consent for participation, were included in the cross-sectional survey. Students absent on the day of the survey were excluded from the study. The minimum required sample size for the quantitative part, calculated at $90 \%$ power and $5 \%$ precision based on the item-specific minimum score difference observed in the pilot study conducted beforehand was 348 adolescents from both the study areas. In the study areas based on total enrolment and proportional attendance two schools were selected from both tribal and non-tribal areas. In each selected school, from each included class one section was selected based on the principle of probability proportional to size. In the selected sections, all the students present were surveyed. Overall, from the four schools, 828 responses ( 397 from schools in the tribal area, and 431 from schools in the non-tribal area) were included for the survey part of the study. In the two schools from tribal area the average enrolment of the tribal students for the selected classes was $30 \%$ of the total. On the other hand, in the non-tribal area the enrolment of tribal students in the schools, on an average was around $11 \%$.

The teachers of the schools who provided written informed consent and residing permanently in the adjoining tribal area (for tribal area schools) and non-tribal rural area (for nontribal area schools) were included for the qualitative part of the study. However, teachers who have taught in the selected schools for a duration of less than one continuous year, or were not teaching the students of the selected classes were excluded. The respondents for the qualitative part were chosen conveniently based on the mentioned inclusion and exclusion criteria. The respondent teachers and students were not involved in the design, conduct, reporting, and dissemination plans of our research. 
TABLE 1 | Components and items in the gender equity questionnaire.

\begin{tabular}{|c|c|c|c|}
\hline \multirow[t]{2}{*}{ Statement } & \multicolumn{3}{|c|}{ Responses } \\
\hline & Agree & Partially agree & Disagree \\
\hline \multicolumn{4}{|l|}{ Privilege of independence (Cronbach's $\alpha=0.774$ ) } \\
\hline 1. Girls should be able to choose to work after marriage to earn their own money & $719(86.8)$ & $62(7.5)$ & $47(5.7)$ \\
\hline 2. Once a woman gets married, she belongs to her husband's family & $511(61.7)$ & $155(18.7)$ & $162(19.6)$ \\
\hline 3. A woman should always obey her husband & $490(59.2)$ & $216(26.1)$ & $122(14.7)$ \\
\hline \multicolumn{4}{|l|}{ Decision roles (Cronbach's $\alpha=0.693$ ) } \\
\hline 4. Girls and boys should decide to do the same amount of housework & $695(83.9)$ & $94(11.4)$ & $39(4.7)$ \\
\hline 5. The husband should decide to buy the major household items & $240(29.0)$ & $267(32.2)$ & $321(38.8)$ \\
\hline 6. Girls should decide on their own about when to get married & $531(64.1)$ & $103(12.4)$ & $194(23.4)$ \\
\hline 7. Boys should decide on their own about when to get married & $517(62.4)$ & $164(19.8)$ & $147(17.8)$ \\
\hline \multicolumn{4}{|l|}{ Access equitability (Cronbach's $\alpha=0.791$ ) } \\
\hline 8. Boys should be fed before girls during meals & $218(26.3)$ & $149(18.0)$ & $461(55.7)$ \\
\hline 9. Boys should go to school over girls & $118(14.3)$ & $142(17.1)$ & $568(68.6)$ \\
\hline 10. Boys should get health services over girls & $93(11.2)$ & $211(25.5)$ & $524(63.3)$ \\
\hline 11. Since girls have to get married, they should not be sent for higher education & $67(8.1)$ & $89(10.7)$ & $672(81.2)$ \\
\hline \multicolumn{4}{|l|}{ Role competence (Cronbach's $\alpha=0.725)$} \\
\hline 12. Only boys can perform regular physical activity/work & $242(29.2)$ & $282(34.1)$ & $304(36.7)$ \\
\hline 13. Girls cannot do well in math or science & $102(12.3)$ & $163(19.7)$ & $563(68.0)$ \\
\hline 14. A woman can only take care of her home, kids and cook for her family & $359(43.4)$ & $281(33.9)$ & $188(22.7)$ \\
\hline \multicolumn{4}{|l|}{ Dominance and control (Cronbach's $a=0.688$ ) } \\
\hline 15. There are times when a husband or a boy needs to beat his wife or girlfriend & $83(10.0)$ & $88(10.6)$ & $657(79.3)$ \\
\hline 16. A man should have the final word in his home and family matters & $214(25.8)$ & $236(28.5)$ & $378(45.7)$ \\
\hline 17. It is necessary to give dowry & $78(9.4)$ & $126(15.2)$ & $624(75.4)$ \\
\hline \multicolumn{4}{|l|}{ Family sustainability (Cronbach's $a=0.673$ ) } \\
\hline 18. Only men should work outside the home to sustain the family & $238(28.7)$ & $112(13.5)$ & $478(57.7)$ \\
\hline 19. A woman should tolerate violence in order to keep her family together & $200(24.2)$ & $225(27.2)$ & $403(48.7)$ \\
\hline 20. A man using violence against his wife is a private matter that should not be discussed outside the couple & 309 (37.3) & $132(15.9)$ & $387(46.7)$ \\
\hline
\end{tabular}

Values within the parentheses represent row percentages corresponding to the number of responses presented outside the parentheses.

\section{Quantitative Measurement}

The quantitative part of the study comprised an assessment of the adolescent's perceptions and beliefs regarding gender equity with the help of a pre-designed pre-tested questionnaire-the questionnaire consisting of socio-demographic details of the respondents, and six selected domains related to gender equity, i.e., perceptions on "privilege of independence", "decision role", "access equitability", "role competence", "dominance and control", and "family sustainability". In the first phase of questionnaire development, the questions pertaining to gender equity were pooled together from other similar validated questionnaires (Men and Gender Equality Policy Project, 2011; Landry et al., 2019; Nanda). The pooled items were then assessed by an expert panel comprising of experts from the fields of Public Health (two), Sociology (one), and Psychology (two). A final brief version with relevant items was generated based on consensus among the experts by excluding redundant questions and incorporating items that were not in the pool but considered relevant by the experts (content validity ratio: 0.88 ). The questionnaire was then pre-tested on a sample of fifty adolescents of same age group, from separate rural co-education schools (one each from tribal and non-tribal areas). The final questionnaire consisted of six domains on gender-equity perceptions of the adolescents, with twenty questions assessed in three-point (i.e., agree, neither agree nor disagree and disagree) Likert-type scale.

Table 1 depicts the gender-equity questions as per domains. The reliability information for each domain is also mentioned.
The questionnaire was translated to Bengali (the local language) by language experts and was back-translated to English by separate experts. The language was refined to achieve translational equivalence. The questionnaire (in English and local language) was administered for the survey among the participating students. The co-education schools were selected based on the number of students and average attendance from the list of the schools. In all the schools, there were multiple sections (two or three) in each class. Classes VIII to XII were chosen for the study. In each class, one section was randomly selected from each school. Classroom-based data collection was done for one section at a time, based on permission of the school authority, and availability of the students.

\section{Qualitative Measurement}

The qualitative component involved twenty-six in-depth interviews (IDIs) with the key informants among the selected teachers. In the non-tribal areas, fourteen teachers were interviewed, and from tribal areas, twelve teachers participated. The IDIs were conducted by the two researchers who had prior experience and training on qualitative research methods and lasted for 35-40 $\mathrm{min}$ in strict adherence to the interview guide developed beforehand. The IDI guide was prepared from the brainstorming sessions with three subject experts. It was further validated by five experts from the disciplines of Public Health (two), Sociology (one), and Psychology (two). The interview guide elicited issues such as "roles and responsibilities associated with each gender," "Unequal privileges among the 
genders," "practice of domination and compulsions," and "access and freedom disparities between genders." Audio recording and field notes were also taken during interviews. Data collection were continued till data saturation when no new information yielded from the interviews.

\section{Analysis}

The survey responses were analyzed in STATA 14.2 (StataCorp, College Station, TX, United States ), and the qualitative data were analyzed through hand-code technique. The responses to each Likert-type item were scored from 1 to 3 . The negative statements were reverse scored. Thus, establishing unidirectional scoring in the questionnaire so that a higher score for each item indicated a favorable perception towards gender equity. The domain-specific scores were calculated by averaging the linear combination of scores for the individual items that belonged to the domain in question, as shown in Table 1. A higher score in each domain indicated a favorable perception towards gender-equity in that domain and vice-versa. Domain specific scores and item scores were individually tested for normality by Shapiro-Wilk test and were found not normally distributed. Spearman correlations were calculated separately for tribal and non-tribal areas, explaining the correlation between the studied domains. Mann-Whitney U test was used to ascertain the statistical difference in different domains between tribal and non-tribal areas and between boys and girls in these areas separately.

For the IDIs, transcript generation and translation from local language to English were done within a day of the interview. Data collection and coding to find the critical segments were done simultaneously. Hand code technique was applied independently by two coders, and themes were generated. Transcripts were read multiple times initially to have a general understanding of the content. Codes were merged and summarized to form themes, and the themes prepared were further put into appropriate domains under the issues explored.

\section{Ethics}

The current study was part of a larger study, which was approved by the Institutional Ethics Committee of Medical College and Hospital, Kolkata. The school's authoritie's permissions were taken before data collection with assent and consent obtained from the study participants.

\section{RESULTS}

\section{Study Participants and Their Characteristics}

The respondent students were within the age group of 14-19 years with a mean ( \pm standard deviation) age of 15.21 $( \pm 1.37)$ years. Participants belonging to scheduled tribes (ST), i.e., the tribal participants were more in the schools from tribal area $(26.70 \%)$ compared to non-tribal area $(8.12 \%)$, and this difference was statistically significant. Around $69.02 \%$ of students from tribal areas schools were female, while in the schools of nontribal settings, and this was $60.09 \%$. The gender differences of participants among the two study areas were statistically significant. The socio-demographic characteristics of the adolescent students are summarized in Table 2. Among the twenty-six teachers interviewed, the majority were Hindu (19), Male (15), and of general caste (14). Nine teachers belonged to the Scheduled Tribe category; six of them were from the tribal areas.

\section{Perceptions of the Students}

Table 3 shows the scores of the adolescents in each of the items and also in each domain, comparing as per setting and gender. Overall, regarding perceptions on the privilege of independence and decision roles, respondents from tribal areas reported a higher score. However, there was a difference in perceptions on decision roles and family sustainability among the girls, which was statistically significant. The girls from tribal areas had a higher score in these domains than their counterparts from nontribal areas. The respondents in general, and boys, in particular, had comparatively poorer scores $(<2)$ in some items like, "Once a woman gets married, she belongs to her husband's family", "A woman should always obey her husband" and "A woman can only take care of her home, kids and cook for her family" irrespective of the area of residence, indicating poorer perception about these issues. Boys also had a lower perception score for items like "The husband should decide to buy the major household items" and "Boys should only perform regular physical activity/work than girls". In general, the respondents from tribal areas had a better perception regarding gender equity compared to non-tribal respondents. But regarding the item "Girls should decide on their own about when to get married", boys from non-tribal areas had a better perception compared to boys from tribal areas. The domain-wise perceptions of the students were correlated. The correlations were comparatively higher among the respondents from the tribal areas. The correlations are summarized in Supplementary Table S1.

\section{Qualitative Assessment}

The major themes that emerged from both tribal and non-tribal areas are depicted in Figure 1. The themes generated were alike for both tribal and non-tribal areas, except some themes exclusive to tribal or non-tribal areas and often discordant. The teachers perceived that "boys have the right to decide when to get married", but particularly in tribal areas the teachers perceived the same about girls. In the tribal areas the teachers perceived that "since girls get married off, education is not a necessity", "contrary to the teachers" opinion from non-tribal areas that "proper education can only help a girl get a job" and become independent. In this context, a female teacher of a school in a non-tribal area stated, "Education is a must for a girl to get a job and to be able to live independently."

The teachers from non-tribal areas also perceived that "women are forced to leave their job after marriage". Deprivation of women was perceived in both settings. In non-tribal areas teachers perceived that "women are deprived of healthcare", and in tribal areas, the teachers felt that "women are forced to work even in ill health. Interestingly, women of child-bearing age were given priority for treatment access in both areas. A male teacher in tribal areas perceived", "In small families, women are left with no choice but to work and take up the household activities, even if 
TABLE 2 | Distribution of students according to socio-demographic characteristics and study area.

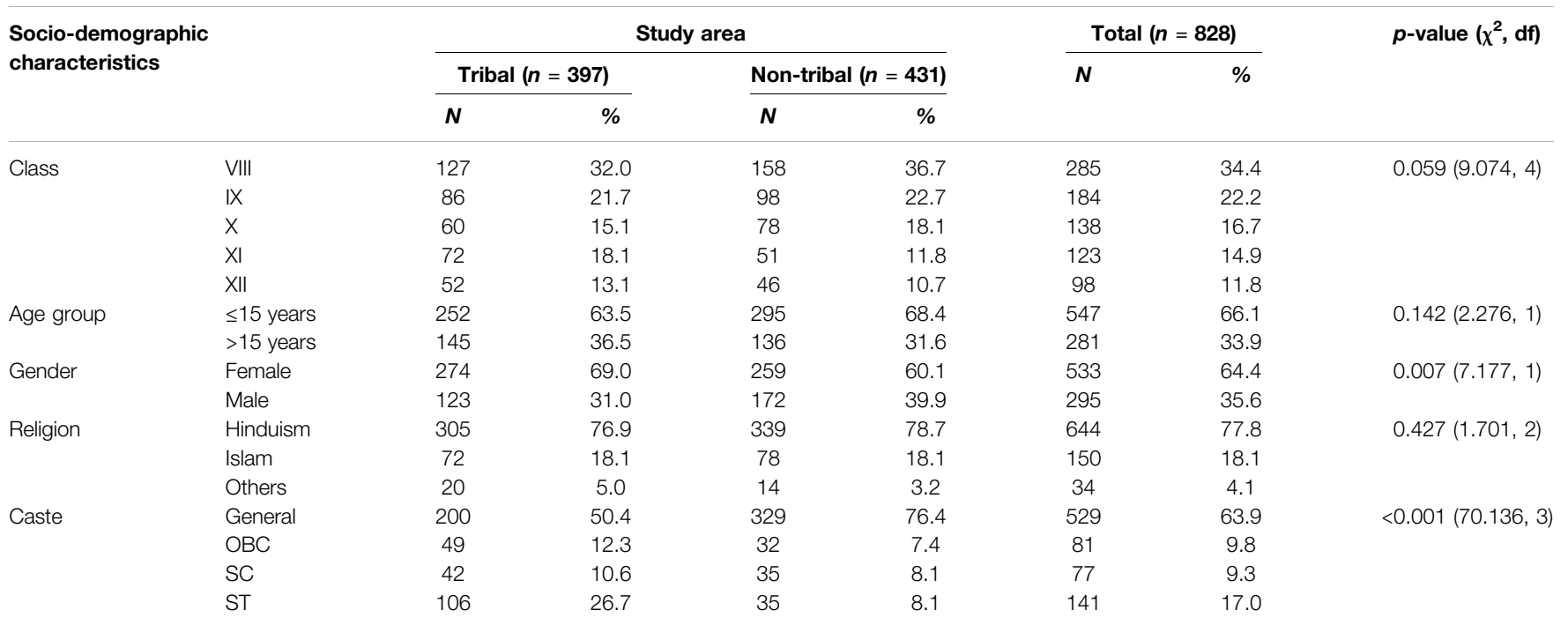

" $n$ " represents the respective sample sizes. " $N$ " implies the absolute frequency, and "\%" indicates the column percentages for the respective categories. " $\chi$ " indicates the chi-square statistic, and "df" indicates degrees of freedom. p-values are calculated based on the chi-square test/test of trend as applicable. OBC, other backward classes, SC, scheduled caste, and ST, scheduled tribes.

they are ill". From non-tribal areas, a senior male teacher commented, "Women are not taken to hospitals or dispensaries; healthcare of a girl or an elderly lady is not important to the family. Only a woman who can and will bear children is given some priority to provide treatment when needed."

It was explored that in some tribal families, women do not tolerate violence, but on the contrary, in non-tribal areas, gender violence often remained hidden, and unreported. A female teacher in tribal areas responded, "Here the women work hard day and night to take care of the family; they do not tolerate the beatings or any abusive treatment from the husband". While men were perceived to be the sole decision-maker in the study areas, in non-tribal areas, teachers opined that "in nuclear families, couples are joint decision-makers regarding family matters."

\section{Integration of the Findings}

Figure 2 represents the integration of qualitative and quantitative findings. The findings were concordant primarily. Regarding access equitability, qualitative discordance was noted for deprivation of women of healthcare and education. Again, in the domain of dominance and control, though the students had a perception in favor of gender equity, the teachers explained how social norms are dominant and deprive women of their rights.

\section{DISCUSSION}

\section{Key Findings}

This mixed-methods study described the perceptions relating to gender-equity among the adolescents in tribal and non-tribal rural areas, contextualizing through the perceptions of their teachers. Access equitability was found to be correlated with role competence, and dominance and control domains. The correlation was stronger among respondents from tribal areas, which was consistent with the study's overall findings. Overall, the respondents from tribal areas had a better perception regarding the equitable privilege of independence among genders. A similar difference was observed for the perception of equity in decision roles, especially among the respondent girls. In general, regarding the financial decision roles of women, respondents from tribal areas had a comparatively better perception. Regarding marriage decisions, a similar trend was observed, with the exception of respondent boys from tribal areas who had a relatively inadequate perception regarding a girl's marriage decisions. Perceptions related to girls access to education were better among the boys from non-tribal areas compared to their counterparts from tribal areas. Overall, the non-tribal respondents had more inadequate perception in favor of women's limited role. The mean score regarding role competence among genders was comparatively lower overall and across genders. Overall, the respondents perceived favorably against gender dominance. Among girls, the perception regarding the equitable role of genders in sustaining a family was better in tribal areas. Among the girls, the tribal respondent's perception against women tolerating violence to save the family was better. The teacher's perceptions were used to contextualize the students' responses. They were mostly concordant in nature, with some exceptions, e.g., regarding dominance and violence-related issues, the teachers perceived differently contrasting the better perceptions exhibited by the students.

\section{What is Already Known and What This Study Adds}

In a previous study among adolescents from a tribal-dominated rural area, Jha et al. demonstrated that girls had a better attitude regarding gender equity compared to boys (Jha et al., 2020). 
TABLE 3 | Domain-wise score comparison among respondents from tribal and non-tribal areas.

Statement

Comparison among boys

Tribal Non-tribal among boys

$\left(n=\quad \begin{array}{lll}n= & \text { Mann- } \\ & \text { whitney }\end{array}\right.$

123)

172)

$\mathbf{U}^{*}$

1. Girls should be able to ch

$\mathbf{1 0 1 2 1 . 0 0}$
10512.00

to earn their own money

2. Once a woman gets married, she belongs to her

husband's family

3. A woman should always obey her husband

$1.27(0.57) \quad 1.19(0.51) \quad 9863.00$

Decision roles

$1.45(0.72) \quad 1.44(0.76)$

$2.42(0.39) \quad 2.47(0.36)$

4. Girls and boys should decide to do the same amount $2.85(0.38) \quad 2.91(0.32)$

of housework

household items

$2.85(0.38) \quad 2.91(0.32) \quad 9926.00$

10284.50

9774.50
9926.00

$1.85(0.71) \quad 1.77(0.64)$

9946.00

married

7. Boys should

married

Access equitability

$2.47(0.72) \quad 2.63(0.64) \quad 9353.00$

9353.00

$2.50(0.69) \quad 2.59(0.63)$

9923.00

8. Boys should be fed before girls during meals

$2.39(0.51) \quad 2.46(0.49)$

$2.25(0.88) \quad 2.34(0.87)$

9661.00

9. Boys should go to school over girls

10. Boys should get health services over girls

$2.44(0.75) \quad 2.50(0.78)$

$2.33(0.78) \quad 2.30(0.79)$

11. Since girls have to get married, they should not be $2.54(0.80) \quad 2.71(0.67)$ sent for higher education

Role competence

$1.79(0.46) \quad 1.84(0.47)$

10023.50

9940.00

10412.00

9522.00

12. Only boys can perform regular physical activity/

$1.63(0.63)$

9829.50

10130.00

$2.33(0.81) \quad 2.42(0.79)$

13. Girls cannot do well in math or science

$1.41(0.57) \quad 1.42(0.56)$

cook for her family

Dominance and control

$2.31(0.61) \quad 2.38(0.59)$

9902.00

10419.00

9857.50

9672.50

15. There are times when
beat his wife or girlfriend

beat his wife or girlfriend family matters

17. It is necessary to give dowry

$1.98(0.85) \quad 1.96(0.86)$

10410.00

$2.45(0.80) \quad 2.54(0.77) \quad 9907.00$

$2.05(0.65) \quad 2.11(0.69)$

$\mathbf{9 9 9 5 . 0 0}$

10407.00

18. Only men
the family

19. A woman should tolerate violence in order to keep $\quad 2.26(0.81) \quad 2.36(0.84) \quad 9745.00$

her family together

20. A man using violence against his wife is a private $\quad 1.94(0.93) \quad 2.00(0.94) \quad 10242.00$ matter that should not be discussed outside the couple

$p$-value

0.466

Comparison among girls

Tribal Non-tribal

$(n=$

274)

$(n=$
$259)$

Mann-
whitney
$U^{*}$

$\begin{array}{lll}0.466 \quad 2.11(0.45) & 2.06(0.39)\end{array}$

$0.896 \quad 2.87(0.45) \quad 2.85(0.47)$

0.113

$0.611 \quad 1.66(0.75) \quad 1.58(0.70)$

$\begin{array}{lll}0.252 & 2.49(0.51) & 2.36(0.49)\end{array}$

$0.085 \quad 2.77(0.54) \quad 2.71(0.60)$

0.335

$2.31(0.83)$

$0.041 \quad 2.42(0.88) \quad 2.22(0.94)$

0.284

$\begin{array}{lll}0.197 & 2.59(0.49) & 2.54(0.49)\end{array}$

$\begin{array}{lll}0.386 & 2.32(0.84) \quad 2.25(0.86)\end{array}$

$0.230 \quad 2.62(0.69) \quad 2.54(0.73)$

$\begin{array}{lll}0.801 & 2.65(0.59) \quad 2.62(0.61)\end{array}$

$0.039 \quad 2.80(0.49) \quad 2.76(0.52)$

$\begin{array}{lll}0.289 & 2.35(0.55) & 2.29 \\ (0.55)\end{array}$

$0.492 \quad 2.29(0.80) \quad 2.31(0.81)$

$0.291 \quad 2.69(0.60) \quad 2.62(0.64)$

$0.795 \quad 2.06(0.82) \quad 1.95(0.80)$

$\begin{array}{lll}0.307 & 2.64(0.43) & 2.57(0.47)\end{array}$

$0.097 \quad 2.78(0.53) \quad 2.71(0.60)$

$0.805 \quad 2.38(0.77) \quad 2.27(0.79)$

$0.258 \quad 2.77(0.52) \quad 2.73(0.55)$

$0.413 \quad 2.33(0.60) \quad 2.22(0.59)$

$\begin{array}{lll}0.796 & 2.52(0.78) & 2.40(0.84)\end{array}$

$0.201 \quad 2.27(0.81) \quad 2.14(0.81)$

$0.610 \quad 2.19(0.90) \quad 2.12(0.88) \quad 33869.00$

Values within the parentheses represent standard deviation corresponding to the mean value presented outside the parentheses. p-values were calculated by Mann-Whitney $U$ test. *Denotes the test statistic observed in each test. The numbers in bold represent the overall effect of these each domains. 


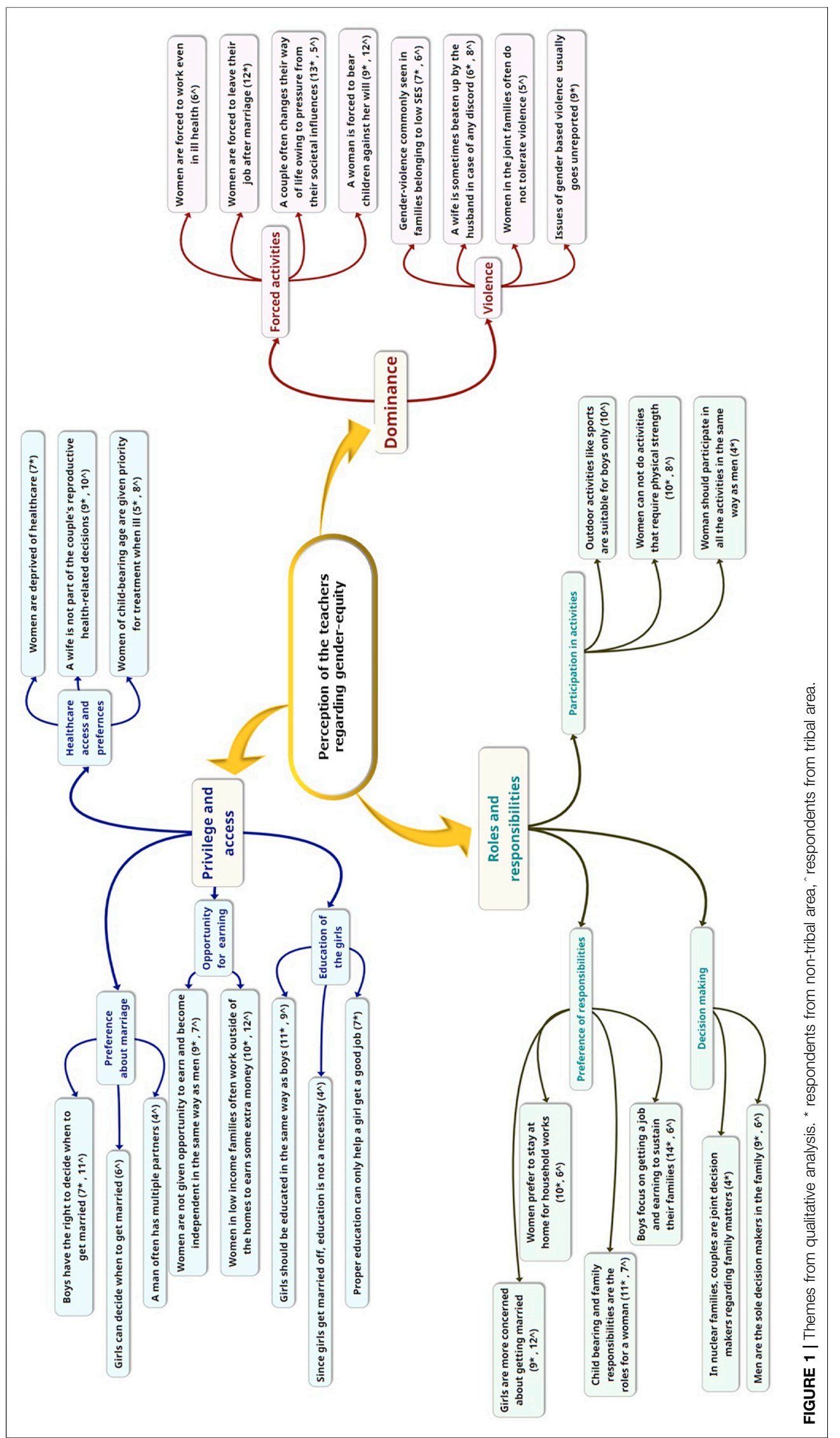




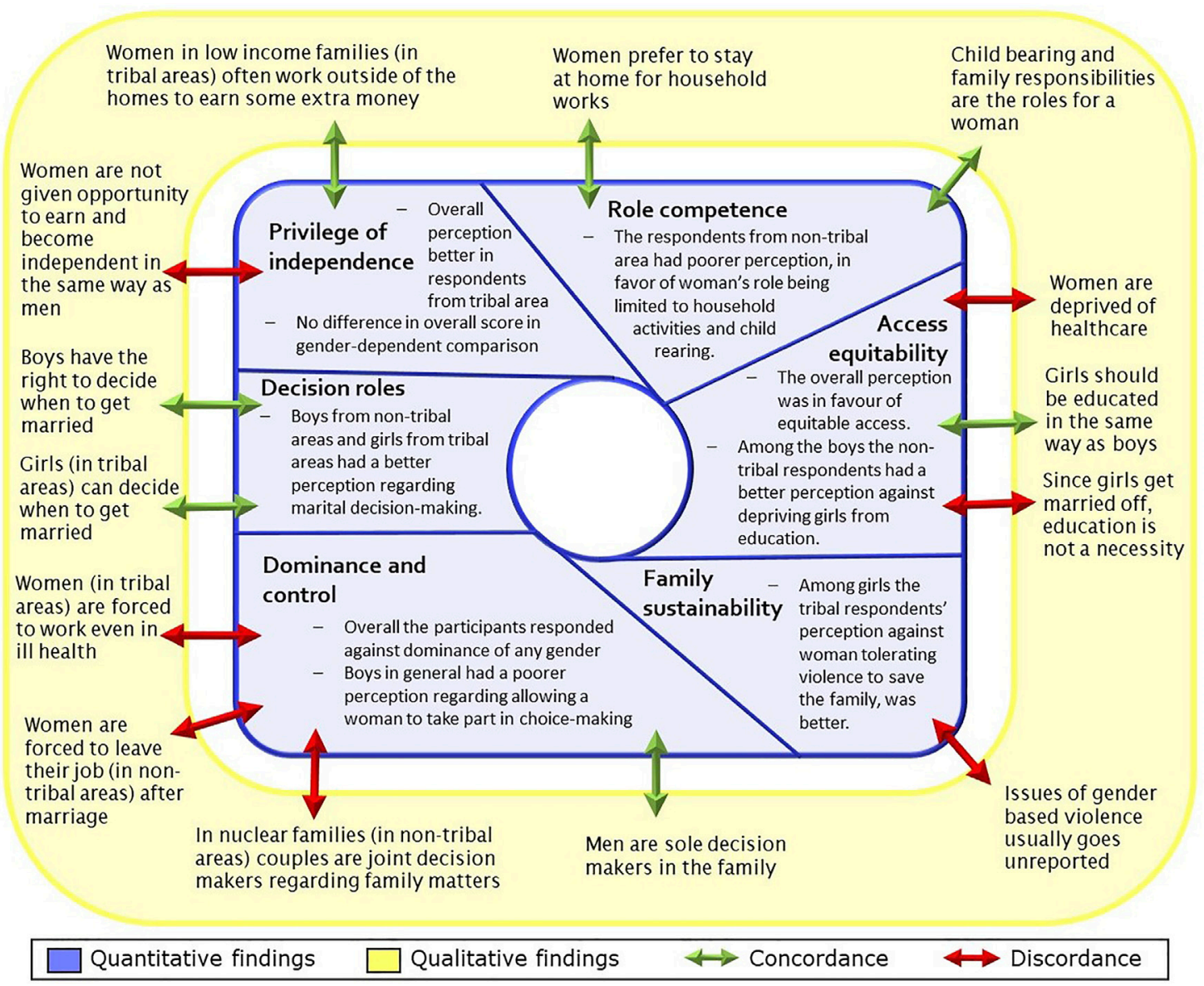

FIGURE 2 | Integration of quantitative findings with qualitative findings.

Landry et al., in their cross-sectional study in Northern India, in a similar way found out that boys were less likely to develop a gender-equitable attitude compared to girls (Landry et al., 2019). However, in the current study, respondent boys had an overall favorable perception of gender-equity in almost all domains. The boys' perceptions were comparatively poorer while discussing male dominance of different roles. Interestingly, among girls, the overall perception related to family sustainability was better in tribal areas. But this was contrasted by the teacher's opinion of frequent under-reporting or noreporting of gender-violence issues. The complex contradiction evidenced can be explained in terms of the dynamics of socioeconomic disadvantage-driven equity in social sustainability and gender roles and normative male dominance in rural areas in general.

Studies have indicated that progressive influence on social institutions focusing on sharing responsibilities among genders and men assuming more non-traditional roles is necessary to overcome gender discrimination (King et al., 2018; England et al., 2020). Bhasin V. discussed the prevalent gender disparities in India and outlined its variation in the tribal communities and the perceived importance of a tribal woman's role extending beyond the segregation of economic outputs (Bhasin, 2007). The current findings support this discourse. The adolescent's perceptions were more in favor of girl's versatile and independent role in the backdrop of their teacher's similar perception of women from tribal areas going out of their homes to work and earn extra money. But on the other hand, teachers from both the study areas felt that girls are not usually given proper opportunities or the motivation to move forward. This was in line with the findings of Keynejad et al. (2018). The student's perceptions about equal access to education for girls were contradicted by the teachers of tribal areas, who perceived education as a mere auxiliary compared to the principal role of marriage. The normative judgment of the preceding social institutions justifies this contradiction (Bhasin, 2007).

In rural areas of the eastern part of the country, healthcare access has been perceived as gender-discriminant in healthcare expenditure or access to facility-based curative or preventive care (Saikia and MoradhvajBora, 2016; Vilms et al., 2017; Jha et al., 2020). The teacher's perceptions explored were, however, in accordance with these findings. The current qualitative results highlight that women's marital 
and reproductive role is considered to be of utmost importance, which is not only a social norm, but also prioritized. Though in a discordant manner, the students perceived mostly in favor of gender-neutral access to services and associated freedom of choice. The tribal areas students had a comparatively better attitude. But regarding girls own choice/decision of marriage, the boys from non-tribal areas had a comparatively better perception. This may indicate an underlining patriarchal system dominating the tribal or marginalized areas, explaining the tribal girls better perception of women's roles, which the elderly members often contradict. The findings are similar to what Walia et al., in their study conducted in a rural area of North India, concluded about men's participation and dominance in reproductive decision making (Walia et al., 2021). The social norms and role-stereotyping of genders have been documented similarly by researchers in India and abroad, emphasizing tribal and disadvantaged populations (Khanna et al., 2018; Willan et al., 2020).

Keynejad et al. reported their young respondents' perception of gender-based violence being a major cause for concern (Keynejad et al., 2018). However, the students' perceptions of dominance in the current study were in stark contrast to what the researchers have demonstrated previously. But the teacher's responses were divergent and directed towards violence and domination by the male gender. The socio-economic perspective of social dynamics can explain this in a tribal context similar to what Dhal S. explored (Dhal, 2018). The teacher's perceived that often women in tribal areas are forced to forego their health priorities, a situation similar to what Sethuraman et al. and Jha et al. explored among rural tribal communities (Sethuraman et al., 2006; Jha et al., 2020).

\section{Strengths and Limitations}

In the current research topic, quantitative and qualitative analyses complemented each other with the advantage of strength in each methodology. As a result, the convergence and divergence in findings provided an understanding. A clear idea of prevalent perceptions within the education system was obtained by including both students and teachers. The current study was probably the first study to explore gender equity perception among adolescents in different rural settings and compare them among tribal and non-tribal areas. The method of conducting the survey and arrangement of the classroom setting attempted to minimize dilution and social desirability. Still, these might have had an impact, resulting in noninterrelated response sets to items in some domains showing lower value of Cronbach's alpha. However, despite the robustness in the mixed-methods design and the study's conduct, the chance of social desirability bias in individual responses cannot be undermined. The results show the situation of the selected areas only. The variation in responses might have occurred due to variation in cognitive levels of the students and age. But these were out of scope for the current study and remained unanswered, paving for further research.

\section{CONCLUSION}

The past half a century has been termed as an era of "gender revolution". Yet, even in the most pragmatic societies, the strive for equity has stalled a bit. The current study is among only a few studies conducted in India that perform a critical investigation in the adolescent students' perception of the multi-dimensional concept of gender-equity, an essential determinant of health. The comparison of responses among tribal and non-tribal areas presents a rural epiphany of gender-equitable perceptions of adolescents. Their teacher's perception, however, highlights the deep-rooted social norms which are functional areas for behavior change interventions. It is observed that health reforms and new models of governance usually do not take into account the gender perspective, which often acts endogenously in the models (Kuhlmann et al., 2015). The current evidence empirically dictates in favor of accounting for gender discrimination while devising newer interventions. Researchers have established gender as a complex determinant of health. Considering the complications posed by the COVID-19 pandemic, Connor et al. have predicted an expanding gender difference in health risks, which can push society to the brink of extreme vulnerability (Connor et al., 2020). Therefore, taking actions to improve gender equity is a way to address women's right to health, which can improve society's overall health through the effective utilization of health resources. Better perceptions from the tribal areas are an opportunity to further enhance on gender-equity. However, boys having a comparatively unfavorable perception of equity for woman's participation in decision making, freedom of working outside, and roles other than child-rearing and family care, etc., are areas where policy-makers need to focus, as this can only intensify gender discrimination in a future society. Formulation of gender-sensitive socially deliverable policies is thus advocated.

\section{DATA AVAILABILITY STATEMENT}

The original contributions presented in the study are included in the article/Supplementary Material, further inquiries can be directed to the corresponding author.

\section{ETHICS STATEMENT}

The studies involving human participants were reviewed and approved by the Institutional Ethics Committee, Medical College and Hospital, Kolkata. Written informed consent to participate in this study was provided by the participant's legal guardian/next of kin.

\section{AUTHOR CONTRIBUTIONS}

AL: Conceptualization, Methodology, Validation, Formal analysis, Investigation, Writing-Original Draft, Visualization, and Supervision. SJ: Conceptualization, Methodology, 
Investigation, Data Curation, Writing-Original Draft, Writing-Review and Editing.

\section{ACKNOWLEDGMENTS}

The authors would like to acknowledge the support provided by the local school authorities and Prof. (Dr.) Urmila Dasgupta. The data collection for the study was supported by active involvement of Dr. Siddhartha Bera and Dr. Atanu Bhattacharjee. Dr. Abhijit Dey, consultant with the World Health Organization provided

\section{REFERENCES}

Bhasin, V. (2007). Status of Tribal Women in India. Stud. Home Community Sci. 1 (1), 1-16. doi:10.1080/09737189.2007.11885234

Brahmapurkar, K. P. (2017). Gender equality in India Hit by Illiteracy, Child Marriages and Violence: a Hurdle for Sustainable Development, Internet. Pan Afr. Med. J. 28, 178, 2017 . cited 2019 Aug 6. doi:10.11604/ pamj.2017.28.178.13993

Braveman, P., and Gruskin, S. (2003). Poverty, Equity, Human Rights and Health. Bull. World Health Organ. 81 (7), 539-545.

Connor, J., Madhavan, S., Mokashi, M., Amanuel, H., Johnson, N. R., Pace, L. E., et al. (2020). Health Risks and Outcomes that Disproportionately Affect Women during the Covid-19 Pandemic: A Review. Soc. Sci. Med. 266, 113364. doi:10.1016/j.socscimed.2020.113364

Creswell, J. W. (2014). Research Design: Qualitative, Quantitative, and Mixed Methods Approaches. 4th ed. Thousand Oaks: SAGE Publications, 273.

Dhal, S. (2018). Situating Tribal Women in Gender Discourse: A Study of the Socio-Economic Roots of Gender Violence in Odisha. Indian J. Public Adm. 64 (1), 87-102. doi:10.1177/0019556117735459

England, P., Levine, A., and Mishel, E. (2020). Progress toward Gender equality in the United States Has Slowed or Stalled. Proc. Natl. Acad. Sci. U S A. 117 (13), 6990-6997. doi:10.1073/pnas.1918891117

Jha, S. S., Dasgupta, A., Paul, B., Ghosh, P., and Biswas, A. (2020). Attitude and Perception of Gender Equity Among Students and Teachers of a Rural School in West Bengal: A Mixed-Method Approach. J. Educ. Health Promot. 9 (1), 330. doi:10.4103/jehp.jehp_597_20

Keynejad, R. C., Mekonnen, F. D., Qabile, A., Handuleh, J. I. M., Dahir, M. A., Haji Rabi, M. M., et al. (2018). Gender equality in the Global Health Workplace: Learning from a Somaliland-UK Paired Institutional Partnership. BMJ Glob. Health 3 (6), e001073. doi:10.1136/bmjgh-2018001073

Khanna, T., Chandra, M., Singh, A., and Mehra, S. (2018). Why Ethnicity and Gender Matters for Fertility Intention Among Married Young People: a Baseline Evaluation from a Gender Transformative Intervention in Rural India. Reprod. Health 15 (1), 63. doi:10.1186/ s12978-018-0500-0

Kim, J. S. (1990). Sex Role Effects on Female Response to Illness. Korea J. Popul. Dev. 19 (2), 135-155.

King, T. L., Kavanagh, A., Scovelle, A. J., and Milner, A. (2018). Associations between Gender equality and Health: a Systematic Review. Health Promot. Int. 35 (1), 27-41. doi:10.1093/heapro/day093check

Kolip, P., and Schmidt, B. (1999) Gender and health in adolescence / by Petra Kolip and Bettina Schmidt. Copenhagen: WHO Regional Office for Europe, 38. Available from: https://apps.who.int/iris/handle/10665/ 108178

Kuhlmann, E., and Annandale, E. (2015). "Gender and Healthcare Policy,". Internet in The Palgrave International Handbook of Healthcare Policy and Governance. Editors E Kuhlmann, RH Blank, IL Bourgeault, and C Wendt (London: Palgrave Macmillan UK), 578-596. cited 2019 Aug 6, Available from:. doi:10.1057/9781137384935_35 the much-needed support in terms of planning issues and resource management. Last but never the least, the authors thank the respondents without whom the whole endeavor would never have succeeded.

\section{SUPPLEMENTARY MATERIAL}

The Supplementary Material for this article can be found online at: https://www.frontiersin.org/articles/10.3389/fsoc.2021.772270/ full\#supplementary-material

Landry, M., Vyas, A., Malhotra, G., and Nagaraj, N. (2019). Adolescents' Development of Gender Equity Attitudes in India. Int. J. Adolescence Youth 25 (1), 94-103. doi:10.1080/02673843.2019.1590852

Mägi, E., Biin, H., Trasberg, K., and Kruus, K. Gender Awareness and Attitudes toward Gender equality Among Students Participating in Teacher Training, 4.

Men and Gender Equality Policy Project. International Men and Gender Equality Survey (IMAGES) [Internet]. 2011 [cited 2021 Dec 4]. Available from: https:// www.icrw.org/wp-content/uploads/2016/10/International-Men-and-GenderEquality-Survey-IMAGES.pdf

Ministry of Health and Family Welfare (2021). National Family Health Survey - 5 (2019 - 2020)| State Fact Sheet: West Bengal. [Internet]. New Delhi: International Institute of Population Sciences. Available from: http://rchiips.org/nfhs/NFHS-5_FCTS/West_Bengal.pdf cited 2021 Dec 4.

Nanda, G. Compendium of Gender Scales. Washington, DC: FHI 360/C-Change. Available from: http://gender.careinternationalwikis.org/_media/c-change_ gender_scales_compendium.pdf.

Phillips, S. P. (2005). Defining and Measuring Gender: A Social Determinant of Health Whose Time Has Come, Internet. Int. J. Equity Health 4 (1), 11, 2005. cited 2019 Oct 27. doi:10.1186/1475-9276-4-11

Rathgeber, E. M., and Vlassoff, C. (1993). Gender and Tropical Diseases: a New Research Focus. Soc. Sci. Med. 37 (4), 513-520. doi:10.1016/0277-9536(93) 90286-d

Saikia, N., Moradhvajand Bora, J. K. (2016). Gender Difference in Health-Care Expenditure: Evidence from India Human Development Survey. PLOS ONE 11 (7), e0158332. doi:10.1371/journal.pone.0158332

Sethuraman, K., Lansdown, R., and Sullivan, K. (2006). Women's Empowerment and Domestic Violence: The Role of Sociocultural Determinants in Maternal and Child Undernutrition in Tribal and Rural Communities in South India. Food Nutr. Bull. 27 (2), 128-143. doi:10.1177/156482650602700204

United Nations (2010). Global Strategy for Women's and Children's Health. Internet. cited 2019 Aug 6, Available from: https://www.who.int/pmnch/ topics/maternal/20100914_gswch_en.pdf?ua=1 .

Vilms, R. J., McDougal, L., Atmavilas, Y., Hay, K., Triplett, D. P., Silverman, J., et al. (2017). Gender Inequities in Curative and Preventive Health Care Use Among Infants in Bihar, India, Internet. J. Glob. Health 7 (2). 020402, 2017 , cited 2019 Aug 6. doi:10.7189/jogh.07.020402

Vlassoff, C. (2007). Gender Differences in Determinants and Consequences of Health and Illness. J. Health Popul. Nutr. 25 (1), 47-61.

Vlassoff, C., and Manderson, L. (1998). Incorporating Gender in the Anthropology of Infectious Diseases. Trop. Med. Int. Health 3(12):1011-1019.doi:10.1111/ j.1365-3156.1998.tb00001.x

Vyas, A. N., Malhotra, G., Nagaraj, N. C., and Landry, M. (2020). Gender Attitudes in Adolescence: Evaluating the Girl Rising Gender-Sensitization Program in India. Int. J. Adolescence Youth 25 (1), 126-139. doi:10.1080/ 02673843.2019.1598450

Walia, M., Mittal, A., and Kumar, D. (2021). Male Participation in Reproductive Health Care of Women and Factors Associated with Interpersonal Relationship: A Cross-Sectional Study in a Rural Community of Ambala 
District in Haryana. Indian J. Public Health 65 (2), 178-184. doi:10.4103/ ijph.IJPH_262_20

Willan, S., Gibbs, A., Petersen, I., and Jewkes, R. (2020). Exploring Young Women's Reproductive Decision-Making, agency and Social Norms in South African Informal Settlements. PLOS ONE 15 (4), e0231181. doi:10.1371/journal.pone.0231181

World Health Organization. WHO | Women and Gender Equity [Internet].WHO. [cited 2021 December 12]. Available from: https://www.who.int/health-topics/ gender\#tab=tab_1

Conflict of Interest: The authors declare that the research was conducted in the absence of any commercial or financial relationships that could be construed as a potential conflict of interest.
Publisher's Note: All claims expressed in this article are solely those of the authors and do not necessarily represent those of their affiliated organizations, or those of the publisher, the editors and the reviewers. Any product that may be evaluated in this article, or claim that may be made by its manufacturer, is not guaranteed or endorsed by the publisher.

Copyright $(2022$ Lahiri and Jha. This is an open-access article distributed under the terms of the Creative Commons Attribution License (CC BY). The use, distribution or reproduction in other forums is permitted, provided the original author(s) and the copyright owner(s) are credited and that the original publication in this journal is cited, in accordance with accepted academic practice. No use, distribution or reproduction is permitted which does not comply with these terms. 